\title{
Correction to: The complete mitochondrial genome of Sinocyclocheilus tingi (Cypriniformes: Cyprinidae): characterization and phylogenetic position
}

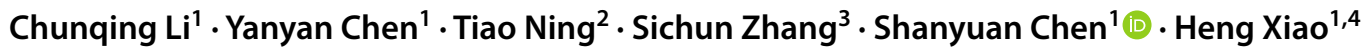

Published online: 31 March 2018

C) Springer Science+Business Media B.V., part of Springer Nature 2018

\section{Correction to: Conservation Genetics Resources https://doi.org/10.1007/s12686-017-0976-x}

Unfortunately, in the original publication of the article, the voucher number in the second paragraph was published erroneously as "YNUSM20160817008". The corrected voucher number should read as "YNUST201406180002".

The original article can be found online at https://doi.org/10.1007/ s12686-017-0976-x.

Shanyuan Chen

chensy@ynu.edu.cn

$\triangle$ Heng Xiao

xiaoheng@ynu.edu.cn

1 School of Life Sciences, Yunnan University,

Kunming 650091, China

2 College of Agricultural Sciences, Kunming University,

Kunming 650214, China

3 Fishery Technology Promotion Station of Jiangchuan County, Jiangchuan 652600, Yunnan Province, China

4 Key Laboratory for Animal Genetic Diversity and Evolution of High Education in Yunnan Province, Yunnan University, Kunming 650091, China 